BLS 33, No 2 2007. DOI: http://dx.doi.org/10.3765/bls.v33i2.3497

(published by the Berkeley Linguistics Society and the Linguistic Society of America)

\title{
Problems in Zapotec Tone Reconstruction ${ }^{1}$
}

\author{
ROSEMARY G. BEAM DE AZCONA \\ RCLT, La Trobe University
}

\section{Introduction}

It seems obvious ${ }^{2}$ that Zapotec languages, and the Otomanguean family to which they belong, have had tonal contrasts for thousands of years, yet most historical studies of Zapotec have ignored tone (excepting Swadesh 1947 and the unpublished work of Joseph Benton). Beam de Azcona (in press) is a historical study which compares five modern varieties and proposes a reconstruction of the ProtoSouthern-Zapotec tonal system. That study is of special interest to Zapotecanist scholars, but challenges encountered in making the reconstruction should be of interest to a wider audience of linguists. The present paper is an account of what these difficulties were and what can be learned from them.

There are two ways in which the study of Southern Zapotec tone is most interesting. First, most studies in historical linguistics focus on segments rather than tone, and historical studies of tone are often more about tonogenesis than about changes that take place within long-standing tonal families. Thus, this study has the potential to add to our knowledge of what kinds of changes affect tone languages as they continue to evolve. Secondly, Zapotec languages are not only closely related in the genetic sense but they also exist in a linguistic area, where changes easily diffuse across genetic boundaries. In the end this and other difficulties encountered in the reconstruction are ones familiar from segmental reconstruction, and prompt questions about the nature of reconstruction itself, what its true end result is, and what benefit it has.

\footnotetext{
1 Thanks to Mark Post, Stephen Morey, Thomas Smith Stark, George Aaron Broadwell, Mark Sicoli, Christian DiCanio, Nicolas Hopkins, John Justeson, Terrence Kaufman, Michael Swanton, Pamela Munro, Heriberto Avelino, and Larry Hyman for informative conversations on topics covered in this paper, which may nevertheless contain errors of my own making.

${ }^{2}$ Tone is pervasive throughout the Otomanguean language family. In many of these languages it also has a high functional load, is intertwined not only with the lexicon but with the grammar, and is involved in complex phonological and morphological rules. A large number of tonal contrasts is also present in many Otomanguean languages. There are no obvious segmental environments to have conditioned any tonogenesis. There are no neighboring language families from which Otomanguean would have acquired tone via diffusion.
} 


\section{Problems Encountered in Making the Reconstruction 1.1. Availability of Reliable Data}

Many Zapotecanist scholars have done a great deal of linguistic work while managing to avoid tone. Most of the linguists who have worked on Zapotecan languages are not native speakers of tone languages, and tone can be difficult to hear and analyze. In developing practical orthographies tonal diacritics are often deemed cumbersome and abandoned. As justification, some Zapotecanists point to the fact that tone has a lower functional load in Zapotec than in some other Otomanguean languages. While a linguist would be ridiculed for writing a phonological description without discussion of segments, and an orthography could not be developed without a consonant inventory, tone is in fact often ignored. In these cases comparative tonal data cannot be gleaned from other linguists' work.

Mostly because of this lack of data, I did not attempt tonal comparisons until I had done enough fieldwork on a second Zapotec language (beginning with Beam de Azcona 2004). To endeavor to make a reconstruction based solely on languages that one has done fieldwork on personally has both advantages and drawbacks. One is usually more confident of one's own data. Whether or not this is warranted, it can at least be said that a single linguist is likely to analyze or misanalyze things in the same way, and so at least the problem will not arise where the same sound or feature is assumed to be a distinct phenomenon in a separate language only because another linguist has analyzed it differently. Doing things this way means starting with a small but solid set of data, but clearly the result will be different than if one had comparable data from a wider range of languages.

Smith Stark (2003) defined four subgroups of Southern Zapotec: Extended Coatec(an), Miahuatec(an), Cisyautepecan, and Tlacolulita. The last of these is a single language about which virtually nothing is known save for Oscar Méndez's field notes from a brief trip there. In an earlier version of a comparative segmental study of Southern Zapotec (Beam de Azcona forthcoming a), as well as the tonal study in question here (Beam de Azcona in press), I concluded that Coatecan and Miahuatecan languages shared a common ancestor separate from Cisyautepecan, and presumably Tlacolulita. However, in more recent work on the segmental topic, and now with access to Méndez's fieldnotes, it has become apparent that Tlacolulita and Coatecan languages share a sound change in which Miahuatecan does not participate. This suggests the possibility that Tlacolulita may be closely related to Coatecan in a genetic sense but that many similarities between Coatecan and Miahuatecan are instead the result of recent contact. The tonal study is based on five varieties of one Coatecan and one Miahuatecan language. It is likely that many changes to the tonal systems of Southern Zapotec languages have happened fairly recently. Taking these factors into account, the lack of a phonological analysis available for Tlacolulita becomes more important, and the reconstruction attempted for Coatecan and Miahuatecan must be viewed differently if in fact they do not share a recent common ancestor and instead show the results of diffused tone changes. 


\section{Problems in Zapotec Tone Reconstruction}

\subsection{Poor Existing Typology of Tone Changes (Versus Tonogenesis)}

We have such a wealth of historical studies of segments that there is a good typology in place for us to judge what types of segmental changes are common or expected. Compared to segmental studies we have relatively few studies of how tones, once they have already come into existence, change over time (but see Morey 2005, Strecker 1979, Bradley 1978:206-233, Weidert 1987, Li 1977). There also exists a conception among linguists that not all tone languages are the same. We think of tone as behaving differently in Africa than in Asia, and pitch contrasts vary widely in their nature in different languages of the Americas. To the extent that these preconceptions are true, can we expect the same types of changes to effect, say, a high tone in a Bantu language as in a Tai-Kadai language? One need only look at the way in which a term like "pitch-accent" is thrown around to know that we have not yet made a clear enough typology of the way pitch can be exploited linguistically to know what types of "tone languages" exist, much less the types of change which can be seen in each type.

We understand segmental change in terms of features. Consonants can vary so widely from each other, with complete or only partial disruption of airflow, several articulators that can be used, and different types of air pressure changes. Consonants can thus be described using long lists of features detailing voicing, place, and manner of articulation. Tones seem more like vowels in their fluidity. While a consonant could be made using tongue, lips, teeth, nose, glottis, and several easily identifiable points along the roof of the mouth, a vowel is basically made with the tongue and the glottis, sometimes with a little help from the lips or nose, and the vowel space is more relative. While the consonant space is intricately divided up with labels like "alveolar ridge" and "velum" the vowel space is chopped up into relative categories like "front", "back", "high", "low". Tones, at first glance, can be described in even less detail than vowels as we describe fundamental frequency along a height metaphor only (high, mid, low, but not front and back).

Sounds generally change in one or very few features while retaining some features of the original sound. We expect consonants to change from voiced to voiceless, or to change their place or manner of articulation, but to otherwise remain the same. We expect $/ \mathrm{s} /$ to become $/ \mathrm{t} /$ or $/ \mathrm{z} /$ or $/ \mathrm{S} /$ but not $/ 6 /$. Common vowel changes involve movement along either the vertical or the horizontal axis, or changes in lip rounding or nasal air flow. While the vowel space is more fluid, we can still imagine a few extreme changes which we would not expect to take place, for example $/ \mathrm{i} />b /$. But what of tonal changes? The main descriptive feature of tones is fundamental frequency. Do we expect tonal changes mostly in the rapidity of vocal fold vibration?

A second division commonly made is between "level" and "contour" tones. Another criterion to consider is whether changes from one category to the other, or within categories, are more common. Is a change from high tone to falling tone more natural than a change from falling tone to rising tone? Strecker (1979) did posit a change from a rising tone to a falling tone in Lanna Tai, but there was an intermediary level stage (Morey 2005:157). Could such a change ever happen di- 
rectly, or would a contour tone nearly always have to pass through another stage, either as a level or as a complex contour (rising-falling or falling-rising) tone before becoming a contour tone with the opposite directionality?

In truth though, there are more features that can be considered for tonal categories, though these vary greatly by language. In a particular language or language group certain tones may also entail voice quality distinctions, changes in duration, and effects on nearby segments and syllables. Tones given the same descriptive labels (high, low, falling, rising) can be realized quite differently in given languages. All of these factors must be taken into account before suggesting global typological generalizations of tonal change. Tones with labels such as "low" and "rising" may share some phonetic similarity in a particular language group, but this may not be true of "low" and "rising" tones elsewhere.

Considering that segmental changes usually result in a sound which still shares some attributes with the original sound, it is useful to consider in more detail how Zapotec tone categories resemble each other in different ways. If multiple tone features pertinent to Zapotec can be described, then it may help in the effort to identify what changes are most likely to take place. We might expect changes between tones which share some feature to be common, but if there appears to be a change between two tones which are unlike each other, it is likely that this happened in two or more stages, with the intermediate tone(s) sharing features with both the modern tone(s) and a tone that is presumed to have existed at an earlier time. With this objective in mind I formulated a list of features shared between Southern Zapotec tones, both the phonetic realizations of their pitch patterns, and other phonological details they hold in common in particular varieties or across the languages studied. Figure 1 shows six phonetic pitch patterns found thus far in Southern Zapotec languages, and lists the connections between each of these tonal categories. Contrastive glottalization is excluded here as it is historically not part of the tonal system, though it has become so in modern Coatec.

The first problem that becomes apparent is that nearly all the tones have something in common with all the other tones. Even the tones which are the most dissimilar to each other, $\lrcorner$ and $Y, Y$ and 1 , are only one degree removed from each other since they bear more striking similarities to other tones which could serve as intermediaries. It is easy to imagine a contour tone shortening to a level tone, which over time could move in a different direction than the original contour. Thus, like vowels, tones would seem to be very fluid in nature, with fewer unnatural changes than consonants, which are more diverse phonologically.

While this exercise virtually failed to find two tones without features in common, it is unclear whether some of the shared features in Figure 1 are stronger than others, and more likely to enable sound change between those tones which share them. 
Figure 1: Properties of Southern Zapotec tones

\begin{tabular}{|c|c|c|c|c|c|}
\hline & 7 "high" & y "high" & 」"low" & ل "low" & 1 "rising" \\
\hline $\begin{array}{l}\text { y } \\
\text { "high" }\end{array}$ & $\begin{array}{l}\text { allotones in } \\
\text { most dialects }\end{array}$ & ---------- & ---------- & ---- & --- \\
\hline $\begin{array}{l}\lrcorner \\
\text { "low" }\end{array}$ & $\begin{array}{l}\text { level pitch } \\
\text { pattern }\end{array}$ & & ----------- & '----------- & |----------- \\
\hline $\begin{array}{l}\checkmark \\
\text { "low" or } \\
\text { "falling" }\end{array}$ & $\begin{array}{l}\text { same effects } \\
\text { on adjacent } \\
\text { syllables in } \\
\text { SBarL }\end{array}$ & $\begin{array}{l}\text {-falling pitch } \\
\text {-same effects } \\
\text { on adjacent } \\
\text { syllables in } \\
\text { SBarL }\end{array}$ & $\begin{array}{l}\text { allotones in } \\
\text { some varie- } \\
\text { ties }\end{array}$ & ----------- & ----------- \\
\hline $\begin{array}{l}1 \\
\text { "rising" }\end{array}$ & $\begin{array}{l}\text { end in high } \\
\text { pitch }\end{array}$ & $\begin{array}{l}\text { end in } \\
\text { high(ish) } \\
\text { pitch }\end{array}$ & $\begin{array}{l}\text {-long and } \\
\text { glottalized in } \\
\text { Coatec } \\
\text {-same effects } \\
\text { on adjacent } \\
\text { syllables in } \\
\text { SBarL } \\
\text {-begin in low } \\
\text { pitch }\end{array}$ & $\begin{array}{l}\text {-long and } \\
\text { glotta- } \\
\text { lized in } \\
\text { Coatec } \\
\text {-begin in } \\
\text { low(ish) } \\
\text { pitch }\end{array}$ & ----------- \\
\hline $\begin{array}{l} \\
\text { "falling" }\end{array}$ & $\begin{array}{l}\text {-not leng- } \\
\text { thened or } \\
\text { glottalized in } \\
\text { Coatec } \\
\text {-begin in high } \\
\text { pitch }\end{array}$ & $\begin{array}{l}\text {-not leng- } \\
\text { thened or } \\
\text { glottalized in } \\
\text { Coatec } \\
\text {-falling pitch } \\
\text { pattern } \\
\text {-begin in } \\
\text { high pitch }\end{array}$ & $\begin{array}{l}\text { end in } \\
\text { low(ish) pitch }\end{array}$ & $\begin{array}{l}\text {-falling } \\
\text { pitch pat- } \\
\text { tern } \\
\text {-end in } \\
\text { low(ish) } \\
\text { pitch }\end{array}$ & $\begin{array}{l}\text { contour } \\
\text { pitch } \\
\text { pattern }\end{array}$ \\
\hline
\end{tabular}

\subsection{Large Number of Correspondence Sets}

Figure 2 shows the tonal correspondences found between the San Baltazar Loxicha (SBalL) and Coatlán dialects of Coatec and the San Agustín Mixtepec (SAM), San Agustín Loxicha (SAL), and San Bartolomé Loxicha (SBarL) dialects of Miahuatec. When glottalization is indicated here for SAM, both checked and rearticulated vowels are found in the same correspondence set, although rising tone does not occur with rearticulated vowels. Each correspondence set is labeled with a letter, and similar correspondence sets which seem to be variations of each other are distinguished by adding a number (A1, A2, etc.). The number of cognates for which each correspondence set has been found for most dialects is given in the last column. A reconstruction is given for the most common correspondences ${ }^{3}$.

\footnotetext{
${ }^{3}$ The reasoning behind the proto-tones reconstructed is found in Beam de Azcona (in press).
} 


\section{Rosemary G. Beam de Azcona}

Figure 2: Correspondences between varieties of Coatec and Miahuatec

\begin{tabular}{|c|c|c|c|c|c|c|}
\hline & SBalL & Coatlanes & SAM & SAL & SBarL & tokens \\
\hline $\left.\mathrm{A}(*\rceil^{2}\right)$ & $1 ?$ & 12 & $7 ?$ & $7 ?$ & 72 & 15 \\
\hline A2 & $y$ & $y$ & $7 ?$ & 72 & 72 & 2 \\
\hline $\left.\mathrm{B}(*\rfloor^{?}\right)$ & $1 ?$ & 12 & \rfloor $?$ & \rfloor $?$ & \rfloor $?$ & 4 \\
\hline $\mathrm{B} 2$ & \rfloor & $\checkmark$ & \rfloor $?$ & \rfloor $?$ & \rfloor $?$ & 7 \\
\hline B4 & 12 & 12 & \rfloor $?$ & \rfloor & \rfloor $?$ & 1 \\
\hline $\mathrm{C}\left(* \wedge^{2}\right)$ & 1 & 1 & 12 & \rfloor$\sim ل$ & $y \sim 1$ & 4 \\
\hline $\mathrm{C} 2$ & 1 & 1 & 1 & \rfloor$\sim \sqrt{ }$ & $y \sim 7$ & 2 \\
\hline C3 & 1 & 1 & 12 & 1 & & 1 \\
\hline $\mathrm{D}(* 1)$ & 1 & 1 & 1 & 1 & \rfloor & 11 \\
\hline D2 & 1 & 1 & $7 ?$ & 1 & \rfloor & 4 \\
\hline D3 & 12 & 12 & 1 & 1 & \rfloor & 2 \\
\hline D4 & 1 & $\sqrt{ }$ & 1 & 1 & \rfloor & 1 \\
\hline $\mathrm{E}(* 1)$ & $y$ & $y$ & 1 & 1 & \rfloor & 6 \\
\hline $\mathrm{F}(* 1)$ & \rfloor & $\checkmark$ & 1 & 1 & \rfloor & 9 \\
\hline $\mathrm{F} 2$ & \rfloor & $\sqrt{ }$ & 1 & \rfloor & \rfloor & 1 \\
\hline $\mathrm{G}(*\rfloor \sim \sqrt{ })$ & \rfloor & J & $\checkmark$ & \rfloor$\sim \checkmark$ & $\checkmark$ & 11 \\
\hline $\mathrm{H}(*\rceil, \mathrm{V})$ & $7 \sim y$ & $7 \sim y$ & & & $y \sim 1$ & 9 \\
\hline $\mathrm{H} 2$ & $7 \sim y$ & $7 \sim y$ & & & 1 & 1 \\
\hline I $(* 7$, VV) & $y$ & $y$ & $\sqrt{ }$ & \rfloor$\sim \sqrt{ }$ & $y \sim 1$ & 19 \\
\hline $\mathrm{I} 2$ & $y$ & $y$ & 1 & \rfloor$\sim \sqrt{ }$ & $y \sim 1$ & 1 \\
\hline I3 & $y$ & $y$ & \rfloor $?$ & \rfloor$\sim V$ & $y \sim 7$ & 1 \\
\hline $\mathrm{I} 4$ & \rfloor & $y$ & 1 & \rfloor$\sim ل$ & $y \sim 1$ & 1 \\
\hline I5 & $y$ & $y$ & $\checkmark$ & \rfloor$\sim \checkmark$ & $7 ?$ & 1 \\
\hline $\mathrm{J}(*\rceil)$ & $y$ & $y$ & 7 & $y$ & 1 & 8 \\
\hline $\mathrm{J} 2$ & $y$ & $y$ & $\checkmark$ & $y$ & 1 & 1 \\
\hline $\mathrm{K}$ & $y$ & $y$ & 1 & \rfloor$\sim \sqrt{ }$ & $\checkmark$ & 1 \\
\hline $\mathrm{L}$ & $y$ & $y$ & $\checkmark$ & 1 & $\checkmark$ & 4 \\
\hline $\mathrm{M}$ & \rfloor & & $\checkmark$ & $1, y$ & & 1 \\
\hline $\mathrm{N}$ & \rfloor & $\checkmark$ & $\checkmark$ & $y$ & $\checkmark$ & 4 \\
\hline N2 & \rfloor & $\checkmark$ & $\checkmark$ & 1 & $\checkmark$ & 3 \\
\hline $\mathrm{O}$ & $y$ & $y$ & & $y$ & $y$ & 1 \\
\hline $\mathrm{P}$ & $y$ & & & 1 & \rfloor & 1 \\
\hline$Q$ & $y$ & $y$ & 1 & 1 & $y \sim 1$ & 1 \\
\hline
\end{tabular}

In all there are thirty-three correspondence sets listed in Figure 2, a large number for a proto-language which I presume to have had three tones (6-9 suprasegmental types once glottalization is factored in). If we count variants (e.g. C1-3) as single types and leave to future work those types which are poorly attested, say fewer than 6 exemplars so far, we are left with correspondence sets A-J. 


\section{Problems in Zapotec Tone Reconstruction}

Focusing on A-J, I have reconstructed high, low, and rising tones, occurring with and without the conditioning environment of glottalization. Besides my assumption that SAM is conservative in having this inventory, there is also currently no reason to reconstruct any other tone. Falling tones in the varieties considered seem to have developed recently from high tone (Coatec) and low tone (SBarL) and there are no mid tones in the varieties examined. Thus there are three tones posited to give rise to ten correspondence sets (leaving for future work any explanation of how sub-types, e.g. D1-4, have developed). More specifically, three tones are posited to give rise to seven unglottalized correspondence sets. Rising tone $(\mathrm{D}, \mathrm{E}, \mathrm{F})$ and high tone $(\mathrm{H}, \mathrm{I}, \mathrm{J})$ are each reconstructed for three separate correspondence sets. To explain how each single tone has split into three patterns, one expects to find conditioning environments, the next problem to address.

\subsection{Loss of Conditioning Environments}

Southern Zapotec languages are quite monosyllabic, having lost nearly all nontonic vowels historically. ${ }^{4}$ Both pre- and post-tonic vowels have deleted. The tone of pre-tonic vowels may have given rise to a register contrast in Coatec (Beam de Azcona forthcoming b), but otherwise appear to have been lost, while the tones from the deleted post-tonic vowels appear to have survived and combined with the tone of the tonic vowel in at least some cases, as shown in Figure 3.

Figure 3: Cognates between Isthmus and Southern Zapotec

\begin{tabular}{|l|l|l|l|}
\hline Isthmus Zapotec & Coatec $($ SBalL) & Miahuatec $($ SAM) & Gloss \\
\hline chònná & chǒn & tzǒn & three \\
\hline màní $^{\text {P }}$ & mǎn & mă $^{\text {? }}$ & animal \\
\hline ràlé & ndǎl & ndxǎl & H-be.born \\
\hline
\end{tabular}

Correspondence sets D-F are all reconstructed with rising tone. Since rising tone is expected to be one of the original Zapotec tones, based partly on the inventory of Isthmus Zapotec, and also appears to occur in some cases as a melding of earlier low followed by high tone, one thought that occurs is that one of D-F might be original rising tone while one or both of the others could be a more recent composition and a result of the vowel loss.

An important issue, addressed below in $\$ 2.1$, is the timing of the Southern Zapotec vowel loss. If it had already taken place by the time of the Proto-SouthernZapotec horizon, the tonal reconstruction is less complicated and less dependent on outside confirmation from other branches. However, if the vowel loss spread areally then tonal changes resulting from the vowel loss happened in already divergent languages. Given the likelihood of the latter scenario, one might expect that original rising tone would be the most likely to persist and that rising tone

\footnotetext{
${ }^{4}$ One exception is the stative prefix $n a$-. It has reduced to $n$ - before consonant-initial roots in Coatec, but sometimes remains a full pre-tonic syllable in Miahuatec. Other than this, pretonic syllables now exist on Southern Zapotec mostly through compounding.
} 
formed through vowel loss might not result uniformly across varieties, since each variety might have responded differently to the loss of tone-bearing syllables. However, words like those in Figure 3 belong to correspondence D, which shows the most agreement between Coatec and Miahuatec. D-F all must have been rising tone at the Proto-Miahuatec stage, but only $\mathrm{D}$ is also rising in Coatec. We can understand this fact either as the result of an already-monosyllabic common ancestor, or else as a common reaction to the areally-spread vowel loss.

With a significant conditioning environment completely gone from the modern languages, one has to look outside of the Southern Zapotec group for guidance. Again, finding reliable tone data is a problem. Tone is marked in the Sierra Juárez (Nellis \& Nellis 1983) and Isthmus (Pickett et al. 1978) Zapotec dictionaries, although not consistently (i.e. many words are recorded without tone) in the latter. Surely a large-scale comparison with these and other Zapotec languages will soon reveal more about the tonal history of the Zapotecan family at large, but for the time being so few cognates have been found in these sources that offering explanations for the patterns found still feels overly speculative.

\section{Larger Problems Brought to the Fore by the Reconstruction}

The process of reconstructing Proto-Southern-Zapotec brings up questions about the nature of reconstruction itself, and causes one to reflect on the reality of language use in Oaxaca over the last few millennia.

\subsection{Timing of Southern Zapotec Vowel Loss}

Further advances in the reconstruction of Southern Zapotec tone will have to look for explanatory conditioning environments to distinguish between correspondence sets $\mathrm{D}, \mathrm{E}$, and $\mathrm{F}$ with rising tone, and $\mathrm{H}, \mathrm{I}$ and $\mathrm{J}$ with high tone. Thus far, there do not appear to be any consonantal conditioning factors. One might imagine, for example, that tones from deleted post-tonic syllables could have "passed through" sonorous consonants more easily than if voiceless obstruents intervened, but looking at the remaining coda consonants there are no solid generalizations to be made. Vowel length, which contrasts in San Agustín Mixtepec, is a possible conditioning environment to distinguish between $\mathrm{H}$ and I, but how these would have differed from $J$ remains unclear. The tones found on lost syllables, particularly post-tonic syllables, are the most likely instigants of unexplained diversity in the modern tonal systems. As explained above, the deletion of post-tonic vowels and a lack of reliable data from other branches of Zapotec still makes finding these generalizations difficult, though this is sure to improve in the coming years as more fieldwork is done on more Zapotec languages. However, while looking for existing polysyllabic Zapotec languages with tone descriptions, one has to wonder

about the relative timing of the vowel loss in Southern Zapotec and what is being aimed for with the reconstruction of the proto-language.

Most Valley Zapotec languages are today monosyllabic, much like Southern Zapotec languages are, but Colonial Valley Zapotec, as documented by Córdova (1578 a\&b), was still polysyllabic little more than four hundred years ago. In the 


\section{Problems in Zapotec Tone Reconstruction}

South it is more difficult to tell what the colonial language was like. There are polysyllabic words cited in colonial sources on the South, and there are also indigenous-produced Zapotec documents from the colonial Southern Sierra, but it appears from these that at the time it was Colonial Valley Zapotec and not the local languages being used administratively. Likewise there are Zapotec loanwords into Spanish which retain Zapotec vowels, such as toponyms from the South, but again these may come from Valley Zapotec. In a very few cases, though by no means overwhelming, now-deleted vowels seem to still appear sporadically on a few words in Peñafiel questionnaires from the Southern Zapotec area dating from the late nineteenth century.

There simply is not enough good evidence to suggest one way or another when the unstressed vowels were lost from Southern Zapotec languages. The overwhelmingly monosyllabic nature of Southern Zapotec roots today would lead us to reconstruct a monosyllabic language via the comparative method, but it seems quite possible that vowel loss spread areally after these languages were already somewhat differentiated. It is difficult to reconstruct phonological material for what is supposed to be a common ancestor, if all of the daughter languages have lost this material. The lost vowels could probably be reconstructed by looking up and out beyond Southern Zapotec to related, conservative languages, but one has to wonder just how much phonological material we ought to be reconstructing based not on daughter languages but instead nieces. Since vowels have been reconstructed fairly reliably for Proto-Zapotec it is also possible to assume the same post-tonic vowels were in place in Proto-Southern-Zapotec, but we lack a reliable reconstruction of tone for Proto-Zapotec and cannot deduce the tones of posttonic syllables in Proto-Southern-Zapotec so easily. We can imagine that the tones from deleted vowels may have sometimes combined with other tones, other times conditioned tonal changes in other ways, and perhaps other times they may have been lost along with their vowels. In sum, the tonal correspondences found in Southern Zapotec today have probably been influenced by these other tones, themselves complicated to reconstruct, in ways that are not insignificant.

The problem of vowel loss in the reconstruction of Proto-Southern-Zapotec is two-fold. The monosyllabic daughter languages would lead us to reconstruct a monosyllabic proto-language. A monosyllabic proto-language is disadvantageous both because it does not show us the potential conditioning environment from the lost syllables, and also because it is not at all clear, and in fact is maybe not even believable, that the most recent common ancestor of Southern Zapotec languages was a monosyllabic language.

\subsection{The Relationship of Coatec and Miahuatec to One Another}

Coatec and Miahuatec are spoken side by side. Coatec is today considerably reduced geographically, as it gives way to Spanish in town after town. Miahuatec is similarly endangered in some locales, but thriving in many more. In part of the Miahuatec-speaking area, including the historical center around Miahuatlán, there is and has been contact with Coatec for as long as anyone can remember. In both 
speech communities it is not uncommon to meet an older adult man who has traveled the region at one time or another for labor or trade purposes, and who has learned to speak the other language. A younger man, or a woman, or any speaker who has not been previously exposed to the other language will not understand, for example, a text recorded in it, if hearing the language for the first time. However, once given real-life exposure to the language intelligibility is fairly easily acquired and the linguistic similarities reveal themselves to the speakers.

Because of their similarity and geographic proximity, a close genetic relationship between Miahuatec and Coatec has been assumed (at least by the few people to ever ponder the question). When I first undertook the tonal reconstruction, the results of another segmental project also led me to believe that Miahuatecan and Coatecan shared a genetic node together. However, revisions of that segmental project (Beam de Azcona forthcoming a) based on new data now suggest a different scenario in which Miahuatec migrated into the South later than Coatec, or at least did not participate in some early changes together. Miahuatec and Coatec do show later shared innovations and it might even be speculated that when they first came into contact in the South they were still mutually intelligible varieties of a single language, but they were also already divergent, distinct varieties used by people with distinct identities.

If this newer hypothesis is correct, that Miahuatec and Coatec are not as much sisters as they are neighboring cousins, then the assumptions behind the reconstruction start to look different. The most recent common ancestor shared by Miahuatec and Coatec may have been spoken long ago in the Valley, and may have sounded quite different than whatever we reconstruct from the modern languages.

\subsection{The Reality of the Comparative Method}

We do not know how recently Miahuatec and Coatec shared a common ancestor, i.e. how closely they are related in the genetic sense. We do not know how recently they lost their unstressed vowels. We can reconstruct a proto-language and call it Proto-Southern-Zapotec, based on data from Coatec and Miahuatec, but we don't know if the label is accurately applied to this exercise and we don't know if the monosyllabic forms which are easiest to reconstruct ever existed. Perhaps what we reconstruct is not a parent language at all, but a composite language, a made-up language with dominant features taken from different modern varieties. Some features reconstructed truly are jointly (or even singly) inherited traits going back to an earlier ancestor language. Others are traits which perhaps once were found only in a weak minority variety may have subsequently spread with lateracquired prestige. We take the features which are most common, or which we know through other means must have pre-dated competing reflexes, and reconstruct them, but it is unsatisfying compared to what the reality must have been.

The earlier students of Indo-European did not realize that the family-tree diagram was merely a statement of their method; they accepted the uniform parent languages and their 


\section{Problems in Zapotec Tone Reconstruction}

sudden and clear-cut splitting, as historical realities...In actual observation, however, no

speech-community is ever quite uniform. (Bloomfield 1984:311)

Bloomfield talks about a previous generation of scholar as buying into the reality of proto-languages. Any linguist will agree, whilst in conversation with another, that ancestor languages were never uniform but were just as complex as modern languages. Having given it a moment's thought, any linguist would agree that a language like Proto-Zapotec not only had geographical dialects but sociolects. There must have been speech indicators that went along with being a member of the nobility or a warrior class. There were priests, housewives, scribes, peasants, intellectuals, cliques of teenagers, and perhaps even muxes (the Isthmus Zapotec word for the openly gay male transvestites of today). They all had their personalities and eccentricities. Some said $/ \mathrm{u} /$ conforming to a trend while others said /o/ and shook their heads at those who were less traditional. "No speech community is ever quite uniform." We know this, but we don't remember it.

So if Proto-Southern-Zapotec is not the real ancestor language of Coatec and Miahuatec, and maybe not even a real language, what is the point of reconstructing it? We reconstruct because reconstruction is a pleasant pastime. We reconstruct because we are driven to emulate our predecessors (and to gauge the importance of the comparative method to the identity of modern Linguistics, one need only consider how often students are told that Linguistics began with Sir William Jones, as if Pānini had never existed). We reconstruct because of the allure of the unknown past, and the possibility of learning about past languages, through our partially-false notion that proto-languages are true ancestors. But even given these flawed motives, reconstruction is still a worthwhile endeavor. By going about the process of comparison we are made keenly aware of the correspondences between languages, the details in which they agree and disagree. And we are made to think about issues like the reality of language contact and areal diffusion, and language variation in ancient times. Even if the proto-language reconstructed is not, taken as a whole, the ancestor of modern daughter languages, individual forms from the composite language may indeed be equivalent to early forms that are ancestors to individual modern forms. These forms were around the region at an earlier time than today, and gave way to the modern forms. That is still true even if they did not exist in a single, impossibly uniform, common ancestor language.

\section{Conclusion}

Reconstruction is a worthwhile endeavor, though one must be careful to conceive it in the right way, carefully and skeptically. If reconstruction is to be undertaken, an overwhelmingly tonal family deserves a tonal proto-language. In order to achieve this, more attention ought to be paid to tone in synchronic descriptions. It is hoped that more tonal descriptions of Zapotec languages, and more reconstruction of other subgroups within Zapotec, will further the efforts began recently with the reconstruction of Southern Zapotec tone discussed here. Such efforts 
Rosemary G. Beam de Azcona

ought to contribute greatly not only to our knowledge of Zapotec historical linguistics, but to the historical and typological study of tone languages at large.

\section{References}

Beam de Azcona, Rosemary G. Forthcoming (a). Proto-Zapotec Coronal Obstruents in Southern Zapotec.

Beam de Azcona, Rosemary G Forthcoming (b). A Grammar of Coatec Zapotec. Berlin: Mouton de Gruyter.

Beam de Azcona, Rosemary G. In press. Un Estudio Comparativo de los Tonos del Zapoteco Sureño. In de Ávila, Alejandro, Ausencia López Cruz, Vicente Marcial and Michael Swanton, eds., Memorias del Coloquio Francisco Belmar: Las lenguas otomangues y oaxaqueñas ante el siglo XXI. Oaxaca: Fondo Editorial IEEPO / INALI / Universidad Autónoma 'Benito Juárez' de Oaxaca / Fundación Alfredo Harp Helú.

Beam de Azcona, Rosemary G. 2004. Introdụcing San Agustín Mixtepec Zapotec. In Carmen Jany, ed. Proceedings of the 7 Annual Workshop on American Indigenous Languages. UC Santa Barbara.

Bloomfield, Leonard. 1984. Language. Chicago: University of Chicago Press.

Bradley, David. 1979. Proto-Loloish. London: Curzon Press (Scandinavian Institute of Asian Studies).

Córdova, P. Fray Juan de. 1987 [1578a]. Arte del Idioma Zapoteco. México: INAH.

Córdova, P. Fray Juan de. 1987 [1578b]. Vocabvlario en Lengva Çapoteca. México: INAH.

Li, Fang Kuei. 1977. A Handbook of Comparative Tai. Oceanic Linguistics Special Publication No. 15. Honolulu: University of Hawaii Press.

Morey, Stephen. 2005. Tonal Change in the Tai Languages of Northeast India. Linguistics of the Tibeto-Burman Area. 28(2):139-202.

Nellis, Neil and Jane Goodner de Nellis. 1983. Diccionario Zapoteco de Juárez. México, D.F.: ILV.

Smith Stark, Thomas C. 2003. Algunas Isoglosas Zapotecas. Actas del III Coloquio Internacional de Lingüistica "Mauricio Swadesh." México, D.F.: UNAM.

Strecker, David. 1979. A Preliminary Typology of Tone Shapes and Tonal Sound Changes in Tai: Te Lān Nā tones. In Therapan L. Thongkum, Pranee Kullavanijaya, Vichin Panupong and M.R. Kalaya Tingsabach, Studies in Tai and Mon-Khmer Phonetics and Phonology. Bangkok: Chulalongkorn University. 171-240.

Weidert, Alfons. 1987. Tibeto-Burman Tonology: A Comparative Account. Amsterdam: John Benjamins. 


\section{Problems in Zapotec Tone Reconstruction}

Rosemary G. Beam de Azcona

RCLT

La Trobe University

Victoria 3086

Australia

rosemarybdea@gmail.com 